\title{
MyD88 and TRIF mediate the cyclic adenosine monophosphate (cAMP) induced corticotropin releasing hormone (CRH) expression in JEG3 choriocarcinoma cell line
}

\author{
Andy Uh ${ }^{1}$, Charles F Simmons ${ }^{1}$, Catherine Bresee ${ }^{2}$, Nasif Khoury ${ }^{1}$, \\ Adrian F Gombart ${ }^{3}$, Richard C Nicholson ${ }^{4}$, Hande Kocak ${ }^{5}$ and \\ Ozlem Equils*1
}

\begin{abstract}
Address: ${ }^{1}$ Ahmanson Department of Pediatrics, Room 4221, Steven Spielberg Pediatric Research Center, Burns and Allen Research Institute, Cedars-Sinai Medical Center, David Geffen School of Medicine at UCLA, Cedars-Sinai Medical Center, Los Angeles, CA 90048, USA, ${ }^{2}$ Samuel Oschin Comprehensive Cancer Institute Biostatistics Core, Cedars-Sinai Medical Center, Cedars-Sinai Medical Center, Los Angeles, CA 90048, USA, ${ }^{3}$ Linus Pauling Institute; Department of Biochemistry and Biophysics; ALS 2011, Oregon State University; Corvallis, OR 97331-7305, USA, ${ }^{4}$ Mothers and Babies Research Center, Hunter Medical Research Institute, John Hunter Hospital, Newcastle, Australia and ${ }^{5}$ Department of Human Genetics, University of Michigan, Ann Arbor, MI, USA

Email: Andy Uh - Andy.Uh@cshs.org; Charles F Simmons - Charles.Simmons@cshs.org; Catherine Bresee - catherine.bresee@cshs.org; Nasif Khoury - nasif.khoury@cshs.org; Adrian F Gombart - Adrian.Gombart@oregonstate.edu;

Richard C Nicholson - Rick.Nicholson@hnehealth.nsw.gov.au; Hande Kocak - hkocak@umich.edu; Ozlem Equils* - ozlem.equils@cshs.org

* Corresponding author
\end{abstract}

Published: 17 July 2009

Reproductive Biology and Endocrinology 2009, 7:74 doi:10.1186/1477-7827-7-74

This article is available from: http://www.rbej.com/content/7/1/74

(C) 2009 Uh et al; licensee BioMed Central Ltd.

This is an Open Access article distributed under the terms of the Creative Commons Attribution License (http://creativecommons.org/licenses/by/2.0), which permits unrestricted use, distribution, and reproduction in any medium, provided the original work is properly cited.
Received: 6 January 2009

Accepted: 17 July 2009

\footnotetext{
Abstract

Background: Classically protein kinase $\mathrm{A}$ (PKA) and transcription factor activator protein I (AP-I) mediate the cyclic AMP (cAMP) induced-corticotrophin releasing hormone (CRH) expression in the placenta. However enteric Gram (-) bacterial cell wall component lipopolysaccharide (LPS) may also induce-CRH expression via Toll like receptor (TLR)4 and its adaptor molecule Myd88. Here we investigated the role of MyD88, TRIF and IRAK2 on CAMP-induced CRH promoter activation in JEG3 cells in the absence of LPS/TLR4 stimulation.

Methods: JEG3 cells were transfected with CRH-luciferase and Beta-galactosidase expression vectors and either empty or dominant-negative (DN)-MyD88, DN-TRIF or DN-IRAK2 vectors using Fugene6 (Roche). cAMP-induced $\mathrm{CRH}$ promoter activation was examined by using a luminometer and luciferase assay. Calorimetric Beta-galactosidase assays were performed to correct for transfection efficiency. Luciferase expression vectors of CAMP-downstream molecules, CRE and AP-I, were used to further examine the signaling cascades.

Results: CAMP stimulation induced AP-I and CRE promoter expression and led to dose-dependent CRH promoter activation in JEG3 cells. Inhibition of MyD88 signaling blocked cAMP-induced CRE and CRH promoter activation. Inhibition of TRIF signaling blocked CAMP-induced CRH but not CRE expression, while inhibition of IRAK2 did not have an effect on CAMP-induced CRH expression.

Conclusion: MyD88 and TRIF exert direct regulatory effect on CAMP-induced CRH promoter activation in JEG3 cells in the absence of infection. MyD88 most likely interacts with molecules upstream of IRAK2 to regulate cAMP-induced $\mathrm{CRH}$ expression.
} 


\section{Background}

Cyclic AMP-protein is a second messenger that mediates the physiologic responses to a number of hormones, neurotransmitters, and drugs. $\beta$-adrenoceptor agonists, prostaglandin $\mathrm{E}_{2}\left(\mathrm{PGE}_{2}\right)$ activate adenyl cyclase; which catalyzes the conversion of ATP to CAMP. CAMP then binds and activates protein kinase A (PKA), which phosphorylates substrates that regulate key cellular functions such as ion channels, contractile proteins and transcription factors.

One of the molecules induced by cAMP is corticotropin releasing hormone (CRH). In the placenta cAMP induces CRH expression via PKA, cAMP response element (CRE) and transcription factor activating protein (AP)-1 signaling [1]. CRH is then thought to lead to positive feedback mechanisms with fetal cortisol and dehydroepiandrosterone (DHEA) production, fetal maturation and initiation of the parturition.

Infection is a well known risk factor associated with preterm delivery [2], and innate immune system receptors, Toll like receptors, via adaptor molecule myeloid differentiation primary response (MyD)88 [3] and TIR-domaincontaining adapter-inducing interferon-beta (TRIF) [3] and their down stream signaling molecule interleukin-1 receptor-associated kinase (IRAK) 2 are expressed in uterus and placenta, and mediate the infection associated inflammatory responses [4-6]. We have previously shown that MyD88 mediates the Toll like receptor (TLR)4lipopolysaccharide (LPS)-induced CRH expression in JEG3 choriocarcinoma cell line [7]. In those experiments we used cAMP as the positive control and observed that inhibition of MyD88 signaling, in the absence of LPS stimulation, blocked the cAMP-induced CRH promoter activation as well. Here, our aim is to further examine the role of MyD88 and TRIF in CAMP-induced CRH promoter activation in the absence of infection or TLR stimulation.

\section{Methods}

\section{Cell lines and reagents}

JEG3 choriocarcinoma cell line was obtained from American Type Tissue Culture Collection (Manaaas, VA) and cultured in MEM (Invitrogen Life Technologies, Carlsbad, CA) supplemented with $10 \%$ fetal bovine serum, $10 \mathrm{mM}$ HEPES, $1 \mathrm{mM}$ sodium pyruvate and $100 \mathrm{nM}$ of penicillin/ streptomycin (Invitrogen Life Technologies). A cell permeable cyclic AMP (CAMP) analog, 8-bromoadenosine 3',5' cAMP was obtained from Sigma-Aldrich (St. Louis, $\mathrm{MO})$.

\section{Expression vectors}

The CRH-luciferase vector, pGL3-CRH 663, was characterized and described previously [8]. Dominant negative (DN) cDNA constructs of MyD88 and interleukin-1 recep- tor-associated kinase (IRAK) 2 have been characterized and described previously [9]. The $\mathrm{NH}_{2}$-terminally deleted DN-MyD88 coding for amino acids 152-296 inhibits IL1 induced NF-kB activation [9]. IRAK2 is downstream to MyD88 and DN-IRAK2 coding for aa 1-96 inhibits MyD88 induces signaling [9]. The pcDNA3 empty vector and pCMV- $\beta$-galactosidase vectors have been described previously [10]. Luciferase data obtained from the cells transfected with pcDNA3 empty vector was used to assess the specificity of dominant negative vectors (DN-MyD88, DN-TRIF) to suppress cAMP-induced luciferase activity. The viral cAMP response element (CRE)-luciferase vector was described by Giebler et al [11]. This vector contains CRE and GC-rich flanks form a critical DNA element (called the viral CRE) that is obligatory for human T cell leukemia virus type 1 (HTLV-1) protein Tax transactivation [11]. Dr. Shizuo Akira generated the dominant negative TIR domain-containing adapter inducing IFN-beta (TRIF) by truncating the full length 712 aa TRIF to 162 aa Toll/Interleukin-1 receptor domain (TIR)-only domain [12]. The AP-1 luciferase construct was kindly obtained from Dr. Phillip Koeffler (Cedars-Sinai Medical Center, UCLA School of Medicine).

\section{Transfection of JEG3 cells}

JEG3 cells were plated at a concentration of 50,000 cells/ well in 24-well plates and cultured in MCDB-131 with $10 \%$ fetal bovine serum overnight. Cells were co-transfected the following day with FuGene6 Transfection Reagent following the manufacturer's instructions. The Roche Fugene6 transfection system is routinely used by our laboratory and others, and does not affect the cell viability or induce cytokine production in the transfected cells [10]. The reporter genes CRH-Luciferase $(0.5 \mu \mathrm{g})$ and either empty vector or dominant negative mutants of MyD88 and TRIF were transfected into the JEG3 cells. Reporter gene CRE-luciferase $(0.5 \mu \mathrm{g})$ was transfected to assess the effect of TLR stimulation on CRE expression. pCMV- $\beta$ galactosidase cDNA $(0.1 \mu \mathrm{g})$ was transfected to normalize the results for transfection efficiency as described earlier [10].

After overnight transfection, the cells were stimulated with various concentrations of CAMP. CRH-luciferase CDNA transfected JEG3 cells were stimulated with cAMP for 5 hrs or $20 \mathrm{hrs}$ in separate sets of experiments. Cells were then lysed and luciferase activity was measured with a Promega kit (Promega, Madison, WI) and a luminometer. The adequacy of the transfection was assessed by cotransfecting the cells with $\beta$-galactosidase vector and performing calorimetric galactosidase assay. This is a very well established and accepted method of assessing the transfection efficiency. The cells transfected with $\beta$-galactosidase are also considered to be transfected with the vector in question, in our case CRH-luciferase vector. $\beta$ - 
galactosidase activity was determined by calorimetric method as described earlier [10]. The luciferase data was corrected for transfection efficiency by dividing the luciferase measurement with the galactosidase measurement. This result was expressed as the relative light unit (RLU).

\section{Statistical analysis}

Each experiment was performed in triplicate or quadruplicate and repeated at least three independent times. To study the effect of the varying combinations and concentrations of cAMP and the DNA-vectors across each assay, one-way ANOVA was used to examine the difference in luciferase units across the different treatment groups. Tukey's test was then used to compare the average luciferase units between each of the treatment groups against the control while properly adjusting for multiple comparisons. The data presented are the results of a representative experiment.

\section{Results}

cAMP induces CRH promoter activation in the JEG3 cells CAMP is known to induce CRH expression in the trophoblasts. We first confirmed and extended those observations in JEG3 cells by transiently transfecting them with CRHluciferase expression vector. We treated the cells with different concentrations of CAMP $(0.1,0.5,1 \mu \mathrm{M})$ for 5 or20 hours and observed that CAMP treatment increased CRH promoter activation in a dose dependent manner and this was evident at $5 \mathrm{~h}$ (data not shown). Based on this data we stimulated the cells with $0.5 \mu \mathrm{M}$ cAMP for $5 \mathrm{hr}$ in the rest of the experiments. The transcription factor AP-1 has been shown to mediate cAMP induced CRH promoter activation in humans [13]. As anticipated cAMP stimulation induced luciferase activity significantly above media treated control in JEG3 cells transiently transfected with AP-1 luciferase vector (Figure 1). Pair-wise comparisons using Tukey's test found that this increase was maximal at $0.3 \mu \mathrm{M}$ cAMP concentration.

\section{DN-MyD88 and DN-TRIF block the CAMP induced CRH promoter activation in JEG3 cells}

Infection induced innate immune responses play a significant role in the pathogenesis of preterm delivery. Innate immune receptors, Toll like receptors, are expressed in the female reproductive system and placenta, and mediate the immune responses to intrauterine infections $[14,15]$. MyD88 is the common adaptor molecule that transmits signals from all TLRs and the IL1 receptor to induce NF- $\kappa B$ activation $[3,16]$.

We have previously shown that MyD88 mediates the LPSinduced, TLR4 mediated, CRH promoter activation in the placenta [7]. In order to assess whether MyD88 plays a direct role in CAMP-induced CRH promoter activation, we cotransfected JEG3 cells with CRH-luciferase and $\beta$-galac-

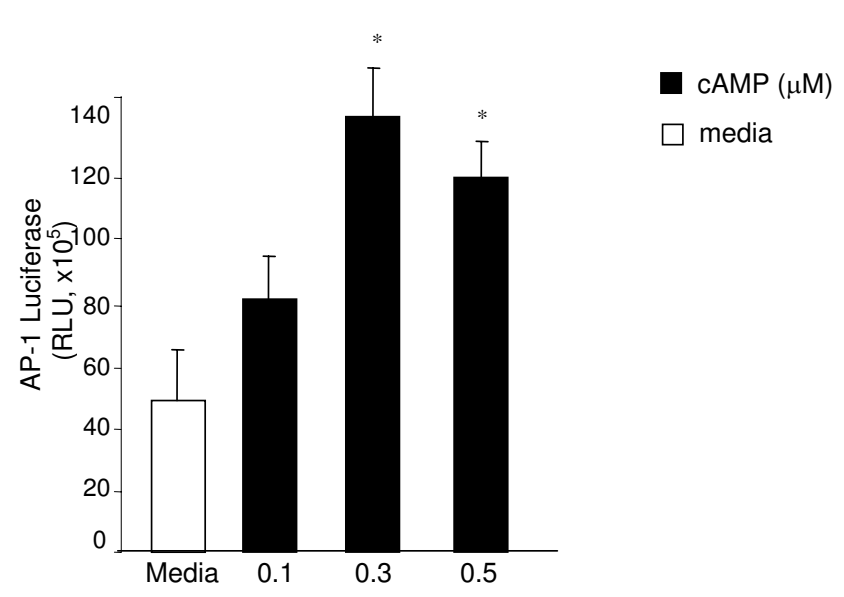

Figure I

The JEG3 cells were transiently transfected overnight with AP-I luciferase and $\beta$-galactosidase expression vectors. The cells were stimulated with CAMP for $5 \mathrm{hr}$ and AP-I promoter activation was assessed by performing luciferase assay. Calorimetric $\beta$-galactosidase assay was performed to correct for the transfection efficiency. Luciferase activity was expressed as relative light unit (RLU). $\left({ }^{*} \mathrm{p}<0.01\right.$ compared to media treated cells). Each experiment was performed in triplicate or quadruplicate and repeated at least three independent times.

tosidase expression vectors and either nonsignaling dominant negative (DN)-MyD88 [9] or empty vector and stimulated the cells with CAMP. There was no increase in cell death after transfection or CAMP treatment as assessed by microscope.

We observed that expression of DN-MyD88 significantly blocked the cAMP-induced CRH expression in a dose dependent manner (Figure 2A). DN-MyD88 effect was maximal at $0.5 \mu \mathrm{M}$ concentration, as the luciferase activity at this concentration was significantly lower than that seen with $0.3 \mu \mathrm{M}$ DN-MyD88 ( $\mathrm{p}=0.03)$ (Figure $2 \mathrm{~A}$ ). These data suggest that inhibition of MyD88 signaling blocks the CAMP-induced CRH promoter activation.

MyD88-independent signaling is mediated via adaptor molecule TRIF, which transduces signals induced by TLR4 and TLR3 [3,17]. MyD88-independent pathways are involved in interferon (IFN) regulatory factor (IRF)-3 activation and subsequent induction of IFN- $\beta$ and IFN-inducible genes and delayed NF-kB activation by TLR4. To test if TRIF plays a role in cAMP-induced CRH promoter activation, we cotransfected the JEG3 cells transiently expressing CRH-luciferase and $\beta$-galactosidase expression vectors with either DN-TRIF or empty vector and stimulated them with CAMP. Pair-wise comparisons using Tukey's test found that expression of both 0.3 and $0.5 \mu \mathrm{M}$ DN-TRIF significantly inhibited the CAMP-induced CRH-luciferase 


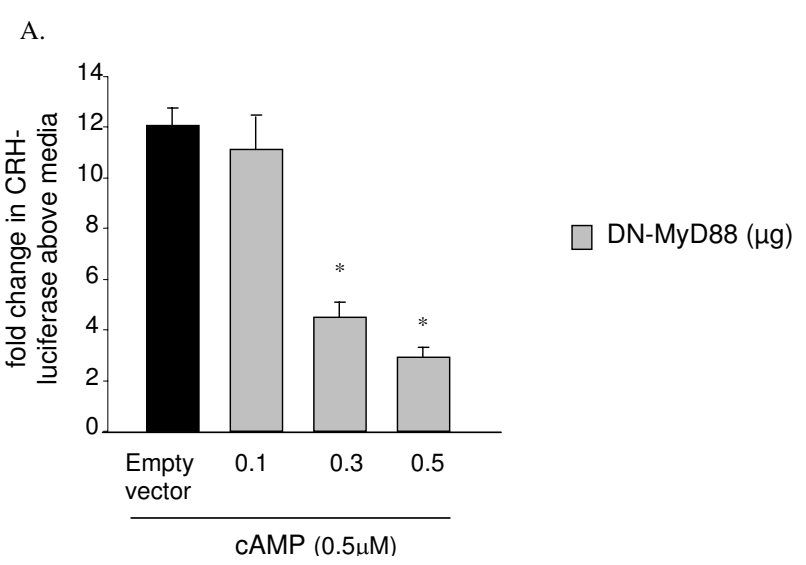

B.

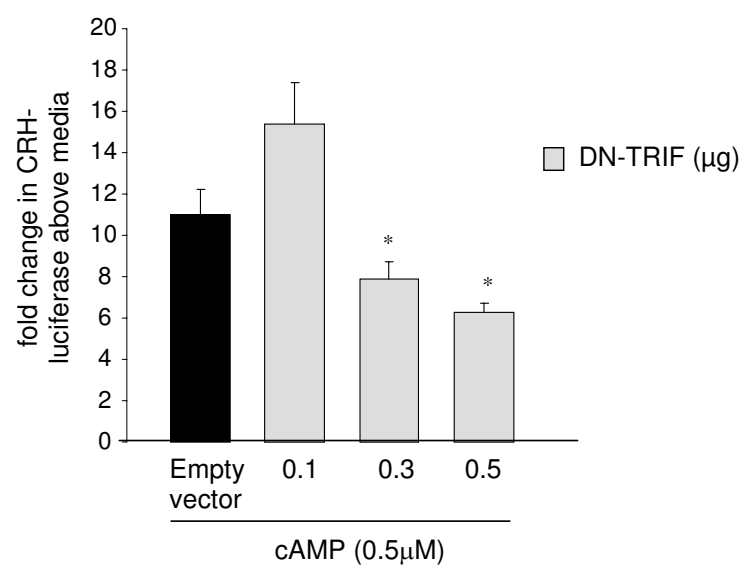

Figure 2

We cotransfected the JEG3 cells with CRH-luciferase and $B$-galactosidase constructs and either empty vector (pcDNA3; $0.5 \mu \mathrm{g}$ ) or various concentrations of DN-MyD88 (Figure 2A) or DN-TRIF (Figure 2B) overnight using Fugene6. The cells were treated with cAMP $(0.3 \mu \mathrm{M})$ or media for $5 \mathrm{~h}$. Luciferase activity was determined to assess $\mathrm{CRH}$ promoter activation. Calorimetric $\beta$-galactosidase assay was performed to correct for the transfection efficiency. $\left({ }^{*} p<0.01\right.$ compared to empty vector transfected cells). The data was presented as fold change in luciferase activity above media treated-empty vector transfected control wells. Each experiment was performed in triplicate or quadruplicate and repeated at least three independent times.

expression ( $\mathrm{p}<0.01$ for each concentration) (Figure 2B). This decrease was maximal at the $0.3 \mu \mathrm{M}$ concentration of DN-TRIF (Figure 2B). These data suggest that inhibition of TRIF signaling blocks the cAMP induced CRH promoter activation.
IRAK2 is downstream to MyD88 and mediates the MyD88 induced NF- $\kappa B$ activation $[3,9]$. We transiently transfected the JEG3 cells expressing CRH-luciferase and $\beta$-galactosidase expression vectors with either empty vector or various concentrations of DN-IRAK2 CDNA. We stimulated the cells with CAMP for 5 hours and examined the CRH promoter activation by performing luciferase assays. We observed that expression of DN-IRAK2 cDNA did not block the cAMP-induced CRH promoter activation (data not shown). These data suggest that MyD88 regulation of cAMP-induced CRH expression is proximal to IRAK2.

\section{DN-MyD88 but not DN-TRIF blocks the CAMP induced CRE expression in JEG3 cells}

The cAMP response element (CRE) is downstream of PKA and mediates the CAMP induced CRH promoter activation in trophoblasts $[1,8,18]$. We questioned whether MyD88 and TRIF regulated CAMP-induced CRE promoter expression. We first confirmed that $5 \mathrm{hr}$ stimulation with cAMP induces CRE activation in a dose dependent manner in JEG3 cells transiently expressing the CRE-luciferase expression vector (Figure 3 ). This increase was maximal at $0.5 \mu \mathrm{M}$ CAMP as CRE-luciferase levels were significantly higher at this concentration over those seen at the 0.3 umol concentration $(\mathrm{p}<0.01)$ (Figure 3$)$.

Next, we tested whether Myd88 and TRIF influences cAMP-induced CRE expression. In JEG3 cells transiently cotransfected with CRE-luciferase vector, expression of DN-MyD88 cDNA significantly decreased the cAMPinduced CRE-luciferase levels in a dose dependent manner ( $p<0.01$ for all concentrations). This decrease was

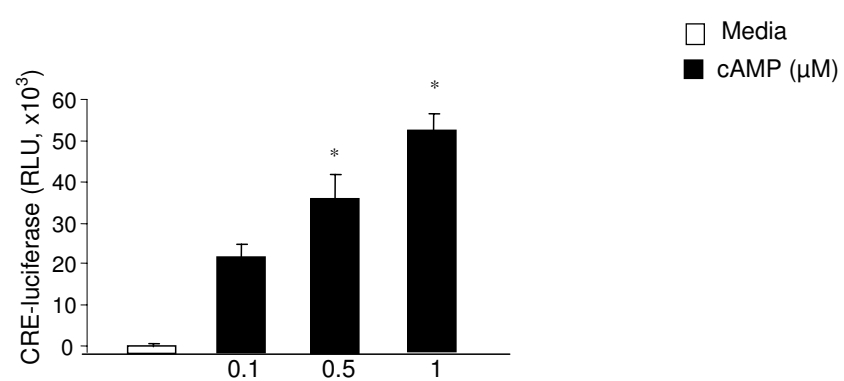

Figure 3

The JEG3 cells were transiently transfected with CRE-luciferase and $\beta$-galactosidase reporter constructs overnight using Fugene6 (Roche) as described under Methods. The cells were stimulated with either cAMP or media. Luciferase assay was performed to assess $\mathrm{CRH}$ promoter activation. Calorimetric $\beta$-galactosidase assay was performed to correct for the transfection efficiency. Luciferase activity was expressed as relative light unit (RLU). $\left(*_{p}<0.01\right.$ compared to media treated cells). Each experiment was performed in triplicate or quadruplicate and repeated at least three independent times. 
maximal at $0.5 \mu \mathrm{M}$ concentration of DN-MyD88; at this concentration of DN-MyD88 cAMP-induced luciferase activity was significantly lower than that observed with the $0.3 \mu \mathrm{M}$ concentration $(\mathrm{p}=0.04)$ (Figure $4 \mathrm{~A}$ ). In contrast, DN-TRIF did not inhibit cAMP-induced CRE promoter activation (Figure 4B).

\section{Discussion}

CAMP is a ubiquitous second messenger that regulates numerous biological processes. Here we show that the innate immune system molecules MyD88 and TRIF regulate the CAMP signaling in trophoblasts. In JEG3 cells, inhibition of MyD88 signaling blocked the CAMPinduced CRE-promoter and CRH-promoter expression;

A.

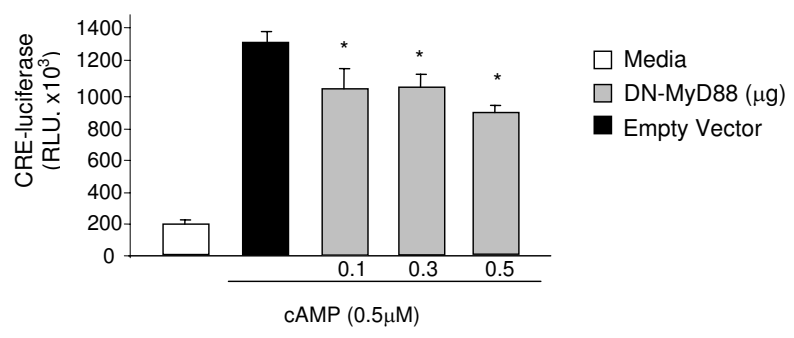

B

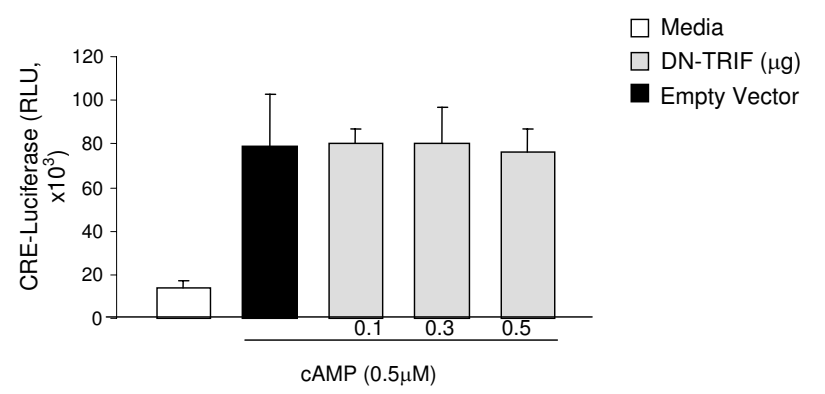

Figure 4

We cotransfected JEG3 cells expressing CRE-luciferase and $\beta$-galactosidase expression vectors with empty vector $(0.5 \mu \mathrm{g})$ and DN-MyD88 (0.1, 0.3, 0.5 $\mu \mathrm{g})$ or DN-TRIF $(0.1,0.3,0.5 \mu \mathrm{g}) \mathrm{cDNA}$ as described above, treated them with CAMP $(0.5 \mu \mathrm{M})$ or media for $\mathbf{5} \mathbf{h}$, and assessed the luciferase activity. Calorimetric $\beta$-galactosidase assay was performed to correct for the transfection efficiency. ${ }^{*} \mathrm{p}<0.01$ compared the cAMP treated empty vector transfected control). Luciferase activity was expressed as relative light unit (RLU). Each experiment was performed in triplicate or quadruplicate and repeated at least three independent times. whereas inhibition of TRIF blocked only the CRH promoter activation.

cAMP is produced in response to hormones and nutrients, and via PKA regulates numerous processes (i.e. cardiovascular function [19], glucose homeostasis [20], adipocyte metabolism [21], growth-factor-dependent cell survival [22], learning and memory [23], immune function [24] and exocytotic processes such as gastric acid secretion [25]). cAMP also regulates reproductive function. Acute steroid biosynthesis is regulated by cAMP induced cholesterol release from lipid droplets and cholesterol transport across the mitochondrial membrane [26]. The initiation and maintenance of sperm motility depends on cAMP and PKA [27]. The gonadotropin induction of ovulation and oocyte maturation are associated with increased cAMP levels in the ovarian follicles [28].

During pregnancy, cAMP has diverse functions. Through its effects on calcium and potassium channels and myosin light chain kinase, cAMP promotes myometrial relaxation [29]. Tocolytic beta-mimetics operate through cAMP to inhibit uterine contractility in preterm labor [30] whereas in the trophoblasts, cAMP induces the release of CRH. $\mathrm{CRH}$ then crosses into the fetus to induce dihydroepiandrosterone (DHEA) release. DHEA is converted into estrogen in the placenta, and estrogen then induces the expression of genes that lead to cervical softening and myometrial contractility [31]. CRH expression has been shown to be higher in women who deliver preterm and increased CRH levels have been proposed to play role in early parturition [32].

In the placenta, cAMP induces CRH expression through activation of PKA, CRE and transcription factor AP-1 $[1,8,18]$. Here we first confirmed that cAMP induces $\mathrm{CRH}$ promoter activation through CRE and AP-1 in the JEG3 cell line and showed that innate immune system molecules, MyD88 and TRIF, play a direct role in CAMPinduced CRH promoter activation in JEG3 cells. Our data suggests that IRAK2 does not play a role in MyD88 regulation of cAMP signaling.

Adenylate cyclases (AC) synthesize cAMP from ATP and these enzymes are found in microbes as well as humans. In microbes, CAMP signaling is involved in the pathogenesis and virulence by regulating microbial metabolism, stress resistance, and maturation [reviewed in [33]]. Our data potentially suggest that the innate immune system molecule, MyD88, may regulate microbial-cAMP signaling and may potentially induce a direct antimicrobial effect. Cirl and colleagues have recently shown that virulent bacteria evolved a mechanism to inhibit the host MyD88 specific signaling to suppress host innate immunity [34]. We propose that microbial pathogens may 
potentially inhibit host cell MyD88 signaling to suppress cAMP signaling to regulate host metabolism, immunity, and cardiovascular function.

cAMP regulates gene transcription via PKA. In the basal state, PKA resides in the cytoplasm as an inactive heterotetramer of paired regulatory (R) and catalytic (C) subunits. cAMP liberates the $\mathrm{C}$ subunits, which passively diffuse into the nucleus and phosphorylate CREB [35]. CREB mediates the activation of cAMP-responsive genes by binding as a dimer to a conserved cAMP-response element (CRE) [36].

cAMP is known to inhibit immune activation in macrophages since 1970s [37]. Scaffold proteins called A-kinase anchoring proteins (AKAPs) are known to mediate cAMP inhibition of immune activation via protein kinase A $[38,39]$. AKAPs also form complexes with other signaling molecules for specificity of signaling. For example, AKAP79 binds to PKA, protein kinase C (PKC), and protein phosphatase 2B. AKAP79 basic regions also bind to membrane vesicles containing acidic phospholipids including phosphatidylinositol-4, 5-bisphosphate [PtdIns(4,5)P2] [40]. MyD88 is recruited to TLR4 by TIRAP, which interacts with phosphatidylinositol-4,5bisphosphate (PtdIns $(4,5) \mathrm{P}_{2}$ ) rich regions of the plasma membrane through its amino-terminal phosphatidylinositol 4,5-bisphosphate (PIP2)-binding domain [41]. MyD88 may potentially interact with an AKAP to regulate PKA function and CAMP induced signaling (Figure 5). Indeed MyD88 has been shown to contain a PKA binding site (personal communication with Dr. Douglas Golenbock, University of Massachusetts Medical School).

\section{Conclusion}

Here we demonstrate that inhibition of MyD88 and TRIF signaling block CAMP-induced CRH promoter activation in the JEG3 cells in the absence of infection. These data add to our previous findings on infection induced placental CRH expression [7] and suggest a direct role for innate immune system adaptor molecules MyD88 and TRIF to regulate CAMP signaling in the absence of infection. Inhibitors of MyD88 signaling are considered as potential anti-inflammatory treatments; our data suggest that it is important to understand the effect of MyD88 on cAMP signaling.

\section{Abbreviations}

(TLR): Toll like receptor; (AP-1): activator protein 1; (TIR): Toll/Interleukin-1 receptor; (TRIF): TIR-domaincontaining adapter-inducing interferon- $\beta$; (TIRAP): TIRdomain-containing adaptor molecule; (MyD88): myeloid differentiation primary response; $(\mathrm{CRH})$ : corticotrophin releasing hormone; (AC): Adenylate cyclases; (cAMP): cyclic adenosine monophosphate; $\left(\operatorname{Ptd} \operatorname{Ins}(4,5) \mathrm{P}_{2}\right)$ : phosphatidylinositol-4,5-bisphosphate; (PIP2): phosphati-

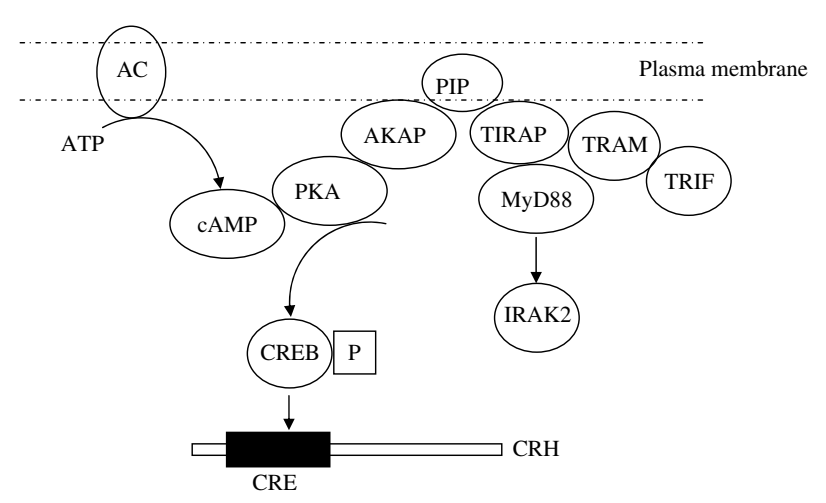

\section{Figure 5}

Proposed Mechanism of MyD88 Regulation of CAMP signalling. MyD88 interacts with TIRAP and PIP2 in the plasma membrane and associates with AKAP. AKAPs are known to regulate CAMP signaling through PKA. MyD88 may regulate cAMP signaling in a complex involving TIRAP-PIP2AKAP. [ATP- Adenosine-5'-triphosphate; AC-adenylate cyclase; PIP2-phosphatidylinositol 4,5-bisphosphate; AKAPA-kinase anchoring proteins; PKA-protein kinase A; CRECAMP-response element; TIRAP-TIR domain containing adaptor molecule; CREB-P-phosphorylated cAMP-response element binding (CREB)]

dylinositol 4,5-bisphosphate; (AKAPs): A-kinase anchoring proteins; (PKA): protein kinase A; (CRE): cAMP-response element.

\section{Competing interests}

The authors declare that they have no competing interests.

\section{Authors' contributions}

AU conducted the transfection, luciferase and galactosidase experiments; CFS provided funds, helped with data analyses and manuscript preparation; СТВ conducted the statistical analyses; AFG helped with the study design, data analyses, and manuscript preparation, he developed and provided help with the CRE and AP-1 vectors; HA helped with data analyses and manuscript preparation; $\mathrm{RN}$ developed the CRH-luciferase vectors, he helped with the study design, data analyses, manuscript preparation; HK and NK conducted the transfection, luciferase and galactosidase experiments; OE initiated and designed the project, analyzed the data, wrote the manuscript. All authors have read and approved the final manuscript.

\section{Acknowledgements}

This work was supported in part by NIH NCRR GCRC Grant (MOIRR00425) to OE and March of Dimes grant (\#6-FY06-329) to OE

\section{References}

I. King BR, Nicholson RC: Advances in understanding corticotropin-releasing hormone gene expression. Front Biosci 2007, | 2:58|-590. 
2. Romero R, Gomez R, Chaiworapongsa T, Conoscenti G, Kim JC, Kim YM: The Role of Infection in Preterm Labour and Delivery. Paediatr Perinat Epidemiol. 200I, I 5 Suppl 2:4I-56.

3. Kawai T, Akira S: Signaling to NF-kappaB by Toll-like receptors. Trends Mol Med 2007, I3:460-469.

4. Abrahams VM, Mor G: Toll-like receptors and their role in the trophoblast. Placenta 2005, 26:540-547.

5. Patni S, Flynn P, Wynen LP, Seager AL, Morgan G, White JO, Thornton CA: An introduction to Toll-like receptors and their possible role in the initiation of labour. BJOG 2007, I | 4: I 326- 1334.

6. Nishimura M, Naito S: Tissue-specific mRNA expression profiles of human toll-like receptors and related genes. Biol Pharm Bull 2005, 28:886-892.

7. Uh A, Nicholson RC, Gonzalez GV, Simmons CF, Gombart A, Smith $\mathrm{R}$, Equils $\mathrm{O}$ : Lipopolysaccharide stimulation of trophoblasts induces corticotropin-releasing hormone expression through MyD88. Am J Obstet Gynecol 2008, 199:el-6.

8. Cheng YH, Nicholson RC, King B, Chan EC, Fitter JT, Smith R: Corticotropin-releasing hormone gene expression in primary placental cells is modulated by cyclic adenosine 3',5'-monophosphate. J Clin Endocrinol Metab 2000, 85:1239-1244.

9. Muzio M, Ni J, Feng P, Dixit VM: IRAK (Pelle) family member IRAK-2 and MyD88 as proximal mediators of IL-I signaling. Science 1997, 278:1612-1615.

10. Zhang FX, Kirschning CJ, Mancinelli R, Xu XP, Jin Y, Faure E, Mantovani A, Rothe M, Muzio M, Arditi M: Bacterial lipopolysaccharide activates nuclear factor-kappaB through interleukin-I signaling mediators in cultured human dermal endothelia cells and mononuclear phagocytes. J Biol Chem 1999, 274:76||-76|9.

II. Giebler HA, Loring JE, van Orden K, Colgin MA, Garrus JE, Escudero $\mathrm{KW}$, Brauweiler A, Nyborg JK: Anchoring of CREB binding protein to the human T-cell leukemia virus type I promoter: a molecular mechanism of Tax transactivation. Mol Cell Biol 1997, I7:5156-5164

12. Yamamoto M, Sato S, Mori K, Hoshino K, Takeuchi O, Takeda K, Akira S: Cutting edge: a novel Toll/IL-I receptor domain-containing adapter that preferentially activates the IFN-beta promoter in the Toll-like receptor signaling. J Immunol 2002, 169:6668-6672.

13. Spengler D, Rupprecht R, Van LP, Holsboer F: Identification and characterization of a 3',5'-cyclic adenosine monophosphateresponsive element in the human corticotropin-releasing hormone gene promoter. Mol Endocrinol 1992, 6: I93I-I941.

14. Pioli PA, Amiel E, Schaefer TM, Connolly JE, Wira CR, Guyre PM: Differential expression of Toll-like receptors $\mathbf{2}$ and $\mathbf{4}$ in tissues of the human female reproductive tract. Infect Immun 2004, 72:5799-5806

15. Kumazaki K, Nakayama M, Yanagihara I, Suehara N, Wada Y: Immunohistochemical distribution of Toll-like receptor 4 in term and preterm human placentas from normal and complicated pregnancy including chorioamnionitis. Hum Pathol 2004, 35:47-54.

16. Janeway CA, Medzhitov R: Innate immune recognition. Annu Rev Immunol 2002, 20:197-216.

17. O'Neill LA, Bowie AG: The family of five: TIR-domain-containing adaptors in Toll-like receptor signalling. Nat Rev Immunol 2007, 7:353-364.

18. Ni X, Nicholson RC: Steroid hormone mediated regulation of corticotropin-releasing hormone gene expression. Front Biosci 2006, II:2909-2917.

19. Movsesian MA: CAMP-mediated signal transduction and sarcoplasmic reticulum function in heart failure. Ann N Y Acad Sci 1998, 853:231-239.

20. Lester LB, Langeberg LK, Scott JD: Anchoring of protein kinase A facilitates hormone-mediated insulin secretion. Proc Natl Acad Sci USA 1997, 94:14942-14947.

21. Collins S, Surwit RS: The beta-adrenergic receptors and the control of adipose tissue metabolism and thermogenesis. Recent Prog Horm Res 200I, 56:309-328.

22. Riccio A, Ahn S, Davenport CM, Blendy JA, Ginty DD: Mediation by a CREB family transcription factor of NGF-dependent survival of sympathetic neurons. Science 1999, 286:2358-236I.

23. Bartsch D, Casadio A, Karl K, Serodio P, Kandel E: CREB I encodes a nuclear activator, a repressor, and a cytoplasmic modula- tor that form a regulatory unit critical for long-term facilitation. Cell 1998, 95:2I I-223.

24. Kammer GM: The adenylate cyclase-cAMP-protein kinase Apathway and regulation of the immune response. Immunol Today 1988, 9:222-229.

25. Yao X, Karam SM, Ramilo M, Rong Q, Thibodeau A, Forte JG: Stimulation of gastric acid secretion by cAMP in a novel alphatoxin-permeabilized gland model. Am J Physiol 1996, 27I:C6I-C73.

26. Sewer MB, Waterman MR: Insights into the transcriptional regulation of steroidogenic enzymes and StAR. Rev Endocr Metab Disord 200 I, 2:269-274.

27. Brokaw C]: Regulation of sperm flagellar motility by calcium and cAMP-dependent phosphorylation. J Cell Biochem 1987 , 35: $175-184$.

28. Törnell J, Billig H, Hillensjö T: Regulation of oocyte maturation by changes in ovarian levels of cyclic nucleotides. Hum Reprod 1991, 6:4II-422.

29. Price SA, López BA: Uterine quiescence: the role of cyclic AMP. Exp Physiol 200I, 86:265-272.

30. Sanborn BM: Hormones and calcium: mechanisms controlling uterine smooth muscle contractile activity. Exp Physiol. 2001, 86(2):223-237

3I. Smith R: Parturition. N EnglJ Med 2007, 356:27I-283.

32. A placental clock controlling the length of human pregnancy. Nat Med 1995, I:460-463.

33. Baker DA, Kelly JM: Structure, function and evolution of microbial adenylyl and guanylyl cyclases. Mol Microbiol 2004, 52:1229-1242.

34. Cirl C, Wieser A, Yadav M, Duerr S, Schubert S, Fischer H, Stappert D, Wantia N, Rodriguez N, Wagner H, Svanborg C, Miethke T: Subversion of Toll-like receptor signaling by a unique family of bacterial Toll/interleukin-I receptor domain-containing proteins. Nat Med 2008, 14:399-406.

35. Gonzalez GA, Montminy MR: Cyclic AMP stimulates somatostatin gene transcription by phosphorylation of CREB at serine. Cell. 1989, 59(4):675-680

36. Comb M, Burnberg NC, Seascholtz A, Herbert E, Goodman HM: A cyclic-AMP- and phorbol ester-inducible DNA element. Nature. 1989, 323(6086):353-356.

37. Bourne HR, Lichtenstein LM, Melmon KL, Henney CS, Weinstein Y, Shearer GM: Modulation of inflammation and immunity by cyclic AMP. Science 1974, 184:19-28.

38. Peters-Golden M: Putting on the brakes: cyclic AMP as a multipronged controller of macrophage function. Sci Signal 2009 , 2:pe37.

39. Dell'Acqua ML, Scott JD: Protein kinase $\mathbf{A}$ anchoring. J Biol Chem 1997, 272: |288|- | 2884

40. Dell'Acqua ML, Faux MC, Thorburn J, Thorburn A, Scott JD: Membrane-targeting sequences on AKAP79 bind phosphatidylinositol-4, 5-bisphosphate. EMBO J 1998, 17:2246-2260.

4I. Kagan JC, Medzhitov R: Phosphoinositide-mediated adaptor recruitment controls Toll-like receptor signaling. Cell 2006, I 25:943-955.

Publish with Bio Med Central and every scientist can read your work free of charge

"BioMed Central will be the most significant development for disseminating the results of biomedical research in our lifetime. "

Sir Paul Nurse, Cancer Research UK

Your research papers will be:

- available free of charge to the entire biomedical community

- peer reviewed and published immediately upon acceptance

- cited in PubMed and archived on PubMed Central

- yours - you keep the copyright 